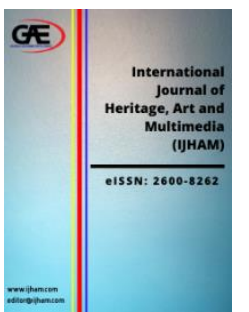

\author{
INTERNATIONAL JOURNAL OF \\ HERITAGE, ART AND MULTIMEDIA \\ (IJHAM) \\ www.ijham.com
}

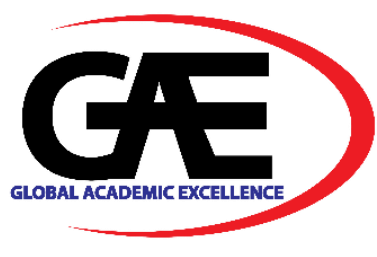

\title{
REDISCOVERING THE DIGITAL SEGMENTATION OF ORGAN DONORS IN MALAYSIA: AN EXPLORATORY REVIEW
}

\author{
Faerozh Madli ${ }^{1}$, Stephen Laison Sondoh $\mathrm{Jr}^{2}$, Andreas Totu ${ }^{3}$, Sharifah Nurafizah Syed Annuar ${ }^{4}$
}

1 Faculty of Business, Economics and Accountancy, Universiti Malaysia Sabah (UMS), Kota Kinabalu, Malaysia. Email: faerozhmadli1987@yahoo.com

2 Faculty of Business, Economics and Accountancy, Universiti Malaysia Sabah (UMS), Kota Kinabalu, Malaysia.

3 Centre for Promotion of Knowledge and Language Learning, Universiti Malaysia Sabah (UMS), Kota Kinabalu, Malaysia

4 Faculty of Business and Management, Universiti Teknologi MARA Sabah (UITM), Kota Kinabalu, Malaysia Corresponding Author

\section{Article Info:}

\section{Article history:}

Received date: 15.10 .2021

Revised date: 15.11 .2021

Accepted date: 10.12.2021

Published date: 13.12 .2021

\section{To cite this document:}

Madli, F., Sondoh Jr, S. L., Totu, A., Syed Annuar, S. N. (2021). Rediscovering The Digital Segmentation Of Organ Donors In Malaysia: An Exploratory Review. International Journal of Heritage, Art and Multimedia, 4 (15), 71-77.

DOI: $10.35631 /$ IJHAM.415006.

This work is licensed under CC BY 4.0

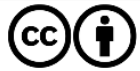

\begin{abstract}
:
Effective insights about market segmentation provide important information for social marketers in formulating a sound marketing plan. This importance could also be observed in the context of the digital segmentation of organ donors in Malaysia. Digital segmentation has become a crucial element in organ donation promotion as fuelled by the rapid shift to the digital world especially social media. In this sense, a sound marketing campaign for organ donation promotion is critically needed due to the low rate of organ donation registrations among Malaysians. Therefore, by focusing on people's inclination to shift to social media and the importance of organ donation in Malaysia, the current study presents a systematic literature review to examine the potential of digital segmentation regarding organ donation promotion via social media. The current study successfully identified university students as the digital target segment for organ donors in Malaysia. This study also observed a massive opportunity to discover a new market segment due to the rapidly increasing number of digital users and the anticipated higher demand for organ donation in the near future. Additional research could optimise the current study findings to further study the effectiveness of organ donation campaigns. Besides that, stakeholders such as the Ministry of Health Malaysia could benefit from current research findings in formulating a sound organ donation marketing campaign.
\end{abstract}

Keywords:

Marketing, Organ Donation, Organ Donors, Digital Segmentation, Malaysia 
Volume 4 Issue 15 (December 2021) PP. 71-77 DOI 10.35631/IJHAM.415006

\section{Introduction}

The marketing experts have recognised that the consumers are uniquely from each other (Haghshens, Abedi, Ghorbani, Kamali \& Harooni, 2013; Nazarov, 2020). In other words, the consumers are not alike nor not same among them. Thus, the market segment is useful to perform in objective to categorising consumers and identifying the niche market for specific products or services (Walsh et al., 2001). Armstrong and Kotler (2005) defined the market segmentation as dividing a market into district groups of buyers who have distinct needs, characteristics or behavior and who might require separate products or marketing mixed. Based on this definition, the main purpose of market segmentation is to align on what the marketer offers with the right customers which is for whom best suited with the product or services.

The concept of commercial segmentation has been widely applied to the social marketing including public health related campaigns as generally (Evans, 2016; Hefler et al., 2020). Andreason (1994) defined the social marketing is the adaption of commercial marketing technologies to programs designed to influence the voluntary behavior of target audiences to improves their personal welfare and that of the society of which they are a part. Evans (2016) mentioned that there are several criteria for effective social marketing segmentation such as being reachable through communication in an affordable way and be substantial enough (large enough) to potentially have a meaningful public health impact. In addition, Evans (2016) also stressed that the rapid growth of digital media technologies has impactfully changed the landscape of segmentation in the last two decades. This phenomenon also can be observed on the rapidly increase the number of social media users across the worldwide including Malaysia (Number of social media users worldwide, 2018; Suruhanjaya Komunikasi dan Multimedia Malaysia, 2017). Recent studies found that the social media could be an effective platform to promote the campaign to increase the organ donation registration (Bail, 2016). However, there are still limited studies determining the effectiveness of social media in promoting organ donation (Blair \& Alfred, 2018).

Besides that, the shortage of organ donors is a pressing issue around the world including Malaysia (Tocher, Kelly \& Neades, 2018; Bastani, 2019). This issue has led to the development of strategic initiatives such as promotion and marketing in order to increase the rate of organ donor registration (Add; Bail, 2016). However, there are limited discussions in context of organ donation associated with marketing and promotion (Akgun, Bilgin, Tokalak, Kut \& Haberal, 2003; Oetjen, Fottler \& Unruh, 2015; Falomir-Pichstor, Berent \& Pereira, 2013; De Groot, Van Hoek, Hoedemaekers, Hoitsma, Schilderman, Smeets \& Van Leeuwen, 2016; Zouaghi, Chouk, \& Rieunier, 2015). Blair and Alfred (2018) mentioned that there is a significant potential of organ donation promotion that still remaining largely unrealized for leveraging the registration as organ donor.

Why is this study significant? As we look to the critical shortage of organ donors registration that pressing around the world including Malaysia, it is calls for formulating a sound marketing campaign to stimulate the registration of organ donation among the citizens. One of important factors to formulate a sound marketing campaign is to identify a suitable market segment. In addition, the highly shifting of public behaviour to the digital world requires the process of segmentation should be include the element of digital behaviour. Therefore, the segmentation that includes the digital behaviour will produce effective outcome in predicting the engagement of campaign with target audiences. Hence, the purpose of this study is to identify or discover 
Volume 4 Issue 15 (December 2021) PP. 71-77 DOI 10.35631/IJHAM.415006

the digital segmentation of organ donors which could be the worthy segmentation for potential of organ donors.

\section{Method}

In order to achieve the aims of this study, the current study conducted a systematic literature review by using a pre-specific search and also inclusion criteria. The researchers use several research terms which are derived from the main keywords; - "organ donation", "organ donor", "market segmentation", "social media segmentation", "Malaysia" and "digital segmentation". The search term or keywords were used to search on several online databased such as Science Direct. In addition, the inclusion criteria that used in the process filtering articles is the intention to register as organ donors. The selected or potential articles were going through the process of reviewed the abstract and also the full text.

\section{Result and Discussion}

After successfully performed the screening process, the current study found several written papers or articles that highly significant in discussing the market segmentation in context social media and organ donation. All of that studies that has been selected are published peer reviewed articles which is ranging from conceptual and descriptive papers.

Based on the elements and factors that discussed on previous articles, the current study come out with suggestion that the suitable digital segmentation for organ donation campaign promotion are public undergraduate university students in Malaysia. Firstly, the university students were chosen as a digital segmentation due to one of important factor in context of Malaysia which is based on the recommended of the Evolution Report 2014, Transplantation Unit, Medical Division, Ministry of Health Malaysia (MOH). In this regard, the Evolution Report 2014 recommended on focusing the category of youth ages for organ donation campaign which in refers to universities students. Youth or 'Belia' in Bahasa Melayu is characterized as people between the age of 15 years and 40 years (Malaysia Youth Policy). In this light, the common age for enrolling in undergraduate programmes in Malaysian public universities in Malaysia is between 20 to 23 years old (Ministry of Higher Education Malaysia, 2019). Furthermore, Department of Statistic Malaysia (2017) mentioned that the category of working age in Malaysia is between 15 years to 64 years old which as seen an increasing number from $67.9 \%$ (2016) to $68.1 \%$ (2017). In fact, in 2017, the population in Malaysia is estimated to grow in rate of $1.3 \%$ for all categories of the population including youth (Current population estimates Malaysia, 2017). Meanwhile, for statistics in context of higher education institution in 2018, found that 338,563 youths are studying for their Bachelor and 99,547 are studying for their Diploma (Ministry of Higher Education Malaysia, 2019).

In addition, the university students as digital segmentation refers to public universities in Malaysia and not private universities in Malaysia because the number of student's enrolment in public universities is higher (MOHE, 2019). Additionally, in term of the usage of health related information on online platform, public universities of student are the highest group of users who access health information on online platform than students of private universities (Montagni et al., 2018). Also, the public universities students were reported to have more ability in access and manage information from social media in compared to the private university students (Abdul Karim et al., 2012). Moreover, in term of usage of social media, students in public universities have higher tendency to use social media platform to access 
Volume 4 Issue 15 (December 2021) PP. 71-77 DOI 10.35631/IJHAM.415006

information compare than students of private universities (Hanum et al., 2013; Mpungose, 2020). Besides that, several previous studies found that here are not much previous studies that found statistically significant correlation between type of faculty and positive behaviour towards organ donation (Feeley \& Servoos, 2005; Canova et al., 2006; Akgün et al., 2003; Perenc et al., 2014; Kocaay et al., 2015). Alternatively stated, the type of faculty enrolled by university student has not significantly influence their positive behavioural towards organ donation context.

Furthermore, the university students are considered as important and valuable segment to target in campaign of organ donation because the students are characteristically young and healthier which made them perfect and suitable for organ donation (Feeley \& Servoss, 2005; Stefanone, Anker, Evans \& Feeley, 2012). Additionally, this segment are often engaged with dangerous activities which sets them to be highly eligible for organ donation death (Feeley \& Servoss, 2005; Stefanone et al., 2012; Usamah \& Anuar, 2017). The willingness of university students to register as organ donors are higher compared to other segments of demographic (Radecki \& Jaccard, 1997; Reubsaet et al., 2005). Moreover, university students are considered to be in the pre-contemplation stage of behavioural change which means many students still lack knowledge and awareness about organ donation and the campaign will have much impact towards their decision to register as organ donors (Feeley \& Servoss, 2005).

Moreover, most undergraduate students are in the early stage of adult life compared to the students that are taking Master Degree and Doctorate Degree who had been exposed to various life experiences which could hinder attitude change (Calrson, 1971). Therefore, this study focused on undergraduate students in Malaysia.

Besides that, the social media plays an important role in life of university students where students frequently use social media for gaining knowledge as well as for academic purpose (Naidoo, Govender, Stead, Mohangi, Zulu \& Mbele, 2018). Majority of university students claimed to have various accounts of social media sites such as Facebook, Twitter, Instagram, YouTube and etc (Tess, 2013). Gritton et al. (2017) mentioned that there is a dramatic increase the usage of social media among youths from 2006 where social media use was recorded at $55 \%$ and the number shows significantly increased to $76 \%$ in 2015 . This is indicate a significant change in favouring the direction to disseminate information for the youth (Gritton et al., 2017). Moreover, Stevens et al. (2016) stated it is estimated that $81 \%$ of youths are users of social media. In context of Malaysia, Yusop and Sumari (2013) stated that $88 \%$ of the Malaysian youth are actively engaged and using social media platform. Based on the aforementioned discussion, it is evident that university students are the appropriate target segmentation due to comprising majority of social media users and are also valuable organ donor candidates. In other words, the university students are the most suitable of digital segmentation for organ donation related campaigns.

\section{Conclusion}

The use of digital segmentation could increase the effectiveness of health campaign outcomes. This also applicable for the organ donation campaign that targeting individual behaviour to have a positive intention or willingness to register as organ donors. The current study suggested that the university students are a worthy and suitable digital segmentation for organ donation promotion campaign. Moreover, the university students are appropriate target segment for 
Volume 4 Issue 15 (December 2021) PP. 71-77 DOI 10.35631/IJHAM.415006

organ donation campaign as they are more likely to become organ donors. Returning to the objective of this study, it is now possible for organ donation campaign to formulate a better digital promotion campaign especially social media platform due to the possibility of targeting the suitable or better segmentation. The better target segment will translate for better effectiveness of organ donation campaign. In addition, future research is needed to establish on how this segment could react to communication campaigns in context of social media or online platforms. For example, the communication campaign that focusing in area of message characteristics. As overall, the result of this study will be useful for relevant authorities such as Ministry of Health Malaysia (MOH), in developing an exceptional online or digital organ donation campaign in Malaysia.

\section{References}

Abdul Karim, A. M., Abdullah, N., Rahman, A. M. A., Noah, S. M., Jaafar, W. M. W., Othman, J., ... Said, H. (2012). A nationwide comparative study between private and public university students' soft skills. Asian Pacific Education Review, 13, 541-548.

Akgün, H. S., Bilgin, N., Tokalak, I., Kut, A., \& Haberal, M. (2003). Organ donation: A crosssectional survey of the knowledge and personal views of Turkish health care professionals. Transplantation Proceedings, 35(4), 1273-1275.

Armstrong, G., \& Kotler, P. (2005). Marketing: An introduction (7th ed.). Upper Saddle River, N.J. Prentice Hall.

Bail, C. A. (2016). Cultural carrying capacity: Organ donation advocacy, discursive framing, and social media engagement. Social Science and Medicine, 165, 280-288.

Bastani, B. (2019). The present and future of transplant organ shortage: Some potential remedies. Journal of Nephrology, 33, 277-288.

Blair, L. S., \& Alfred, M. S. (2018). Organ transplantation and the Uniform Anatomical Gift Act: A Fifty-Year Perspective. Hastings Center Report, 48(2), 14-18.

Canova, D., M, D. B., Ruminati, R., Ermani, M., Naccarato, R., \& Burra, P. (2006). Understanding of and attitudes to organ donation and transplantation: A survey among Italian university students. Clinical Transplantation, 20, 307-312.

Carlson, R. (1971). Where is the person in personality research?. Psychological Bulletin, 75(3), 203-219.

De Groot, J., Van Hoek, M., Hoedemaekers, C., Hoitsma, A., Schilderman, H., Smeets, W., \& Van Leeuwen, E. (2016). Request for organ donation without donor registration: A qualitative study of the perspectives of bereaved relatives. BMC Medical Ethics, 17(1), $1-14$.

Department of Statistics Malaysia. (2017). My Local Stats. Retrieved from https://www.dosm.gov.my/v1/index.php?r=column/cthree\&menu_id=UEg1NkpJUFY zRzBKclE4V2JEb2I3QT09

Evalution Report, $11^{\text {th }}$ Report of National Transplant Registry. (2014). Minitry of Health Malaysia.

Evans, W. D. (2016). Social marketing research for global public health: Methods and technologies. New York, NY: Oxford University Press.

Falomir-Pichastor, J. M., Berent, J. A., \& Pereira, A. (2013). Social psychological factors of post-mortem organ donation: A theoretical review of determinants and promotion strategies. Health Psychology Review, 7(2), 202-247.

Feeley, T. H., \& Servoss, T. J. (2005). Examining college students' intentions to become organ donors. Journal of Health Communication, 10(3), 237-249. 
Volume 4 Issue 15 (December 2021) PP. 71-77 DOI 10.35631/IJHAM.415006

Gritton, J., Rushing, S. C., Stephens, D., Dog, T. G., Kerr, B., \& Moreno, M. A. (2017). Responding to concerning posts on social media: Insights solutions from American Indian and Alaska native youth. The Journal of National Centre, 24(3), 63-87.

Haghshenas, L., Abedi, A., Ghorbani, E., Kamali, A., \& Harooni, M. (2013). Review Consumer Behaviour and Factors Affecting on Purchasing Decisions, Singaporean Journal of Busienss Economics and Management Studies, 1(10), 17-24.

Hanum, P. P., Silvia, H., Donny, E., \& Reza, C. (2013). Effect of social media on website popularity: Difference between public and private universities in Indonesia. World of Computer Science and Information Technology Journal (WCSIT), 3(2), 32-37.

Hefler, M., Kerrigan, V., Grunseit, A., Freeman, B., Kite, J., \& Thomas, D. (2020). FacebookBased Social Marketing to Reduce Smoking in Australia's First Natiosn Communities: An Analysis of Reach, Shares and Likes. Journal of Medical Internet Reseacrh, 22(12), $1-13$.

Kocaay, A. F., Celik, S. U., Eker, T., Oksuz, N. E., Akyol, C., \& Tuzuner, A. (2015). Brain death and organ donation: Knowledge, awareness, and attitudes of medical, law, divinity, nursing, and communication students. Transplantation Proceedings, 47(5), 1244-1248.

Ministry of Higher Education Malaysia. (2019). Statistik Pendidikan Tinggi 2018.

Montagni, I., Cariou, T., Feuillet, T., Langlois, E., \& Christophe, T. (2018). Exploring digital health use and opinions of university students: Field Survey Study. JMIR Mhealth and Uhealth, 6(3), 1-13.

Mpungose, C. B. (2020). Are social media sites a platform for formal or informal learning? students' experiences in institutions of higher education. International Journal of Higher Education, 9(5), 300-311.

Naidoo, D., Govender, P., Stead, M., Mohangi, U., Zulu, F., \& Mbele, M. (2018). Occupational therapy student's use social media for professional practice. African Journal of Health Professions Education, 10(2), 101-105.

Nazarov, A. D. (2020). Impact of Digital Marketing on the Buying Behavior of Consumer. Advances in Economics, Business and Management Reseacrh, 156.

Number of social media users worldwide from 2010 to 2021 (in billions). (2018). Statista. Retrieved from https://www.statista.com/statistics/278414/number-of-worldwidesocial-network-users/

Oetjen, D., Fottler, M. D., \& Unruh, L. (2015). Determinants of the use of health plan information in formulating health plan selection decisions. Health Marketing Quarterly, 20(3), 55-79.

Perenc, L., Radochonski, M., \& Radochonski, A. (2014). Knowledge and attitudes of Polish university students toward organ donation and transplantation. Psychology, Health \& Medicine, 17(6), 667-673.

Peterson, R. (2001). On the use of college students in social science research: Insights from a second-order meta-analysis. Journal of Consumer Research, 28(3), 450-461.

Radecki, C. M., \& Jaccard, J. (1997). Psychological aspects of organ donation: A critical review and synthesis of individual and next-of-kin donation decisions. Health Psychology, 16(2), 183-195.

Reubsaet, A., Brug, J., Nijkamp, M. D., Candel, M. J. J. M., Van Hooff, J. P., \& Van Den Borne, H. W. (2005). The impact of an organ donation registration information program for high school students in the Netherlands. Social Science and Medicine, 60(7), 14791486. 
Volume 4 Issue 15 (December 2021) PP. 71-77 DOI 10.35631/IJHAM.415006

Stefanone, M., Anker, A. E., Evans, M., \& Feeley, T. H. (2012). Click to "Like" Organ Donation: The use of online media to promote organ donor registration. Progress in Transplantation, 22(2), 168-174.

Stevens, R., Gilliard-Matthews, S., Woods, M. K., \& Brawner, B. M. (2016). The digital hood: Social media use among youth in disadvantaged neighborhoods. New Media \& Society, 19(6), 1-18.

Suruhanjaya Komunikasi dan Multimedia Malaysia (SKMM). (2017). Internet Users Survey 2017. Selangor. Malaysia.

Tess, P. A. (2013). The role of social media in higher education classes (real and virtual)-A literature review. Computers in Human Behavior, 29(5), A60-A68.

Tocher, J., Kelly, D., Neades, B., \& Smith, G. D. (2018). The role of the organ donor transplant co-ordinator and the emergence of specialist nurses-organ donation, in the United Kingdom. Journal of Clinical Nursing, 28(9-10), 2020-2027.

Usamah, N. F., \& Anuar, F. I. (2017). What draws you here? Intention of youth's participation in adventure tourism activities. Journal of Tourism, Hospitality \& Culinary Arts, 9(2), $153-162$.

Walsh, G., Hennig-Thurau, T., Wayne-Mitchell, V., \& Wiedman, K-P. (2001). Consumers' Decision-Making Style as a Basis for Market Segmentation. Journal of Targeting, Measurement and Analysis for Marketing, 10(2), 117-131.

Yusop, D. F., \& Sumari, M. (2013). The use of social media technologies among Malaysian youth. Procedia - Social and Behavioral Sciences, 103, 1204-1209.

Zouaghi, S., Chouk, I., \& Rieunier, S. (2015). Promoting organ donation through the "intensity of discussions" with next of kin: Role of superstition, taboo of death and personality variables. Recherche et Applications En Market 